\title{
Teachers' knowledge, practice, and identity: essential aspects of teachers' learning
}

\author{
João Pedro da Ponte
}

Published online: 11 November 2011

(c) Springer Science+Business Media B.V. 2011

The issues of mathematics teacher development and mathematics teacher learning have a central place in the Journal of Mathematics Teacher Education [JMTE]. Therefore, it may be instructive to come back periodically to these notions and reflect on the ways they are being addressed by researchers in mathematics teacher education.

Let me begin by saying that I regard teacher development and teacher learning as equivalent expressions. Researchers use one or another according to their preferences, mostly derived from the conceptual fields that they draw upon. The word "development" perhaps points more clearly to the internal processes of change of the developing person, whereas "learning" is compatible with a wider range of perspectives in which internal processes and external influences have varying roles. But these are rather subjective impressions, and other readers may connect these two words to other meanings, or see no difference whatsoever.

The development or learning processes addressed by mathematics education researchers vary widely. Many researchers focus on knowledge issues, as, for example, knowledge of mathematical content and processes, knowledge of the mathematics curriculum, knowledge of students, and knowledge of mathematics teaching. Others look at teachers' practices, what teachers do in their professional roles and how they do it. Finally, others look at teachers' identity, who the teachers are, both as unique persons and in relation to their professional communities. We may argue that all three foci are fundamental. Without sound and potent mathematical and professional knowledge, we cannot imagine teachers promoting the progress of their students in an adequate way. Without the ability to carry our professional practice aligned with curriculum orientations and adjusted to the needs and conditions of each group of students, the teacher will not fulfill the expectations of the school, students, parents, and society. Also, without a strong professional identity that provides resonance with the values of their professional community and the means for further development, teachers will not have the necessary emotional, social, cultural, and

\section{J. P. da Ponte (凹)}

Instituto de Educação da Universidade de Lisboa, Alameda da Universidade, 1649-013 Lisboa, Portugal

e-mail: jpponte@ie.ul.pt 
cognitive conditions to carry out their demanding job in a reflective and responsible manner, always striving for improving their practice and improving themselves.

The studies that focus on teacher knowledge have a long tradition in the field of mathematics teacher education. Past volumes of JMTE show that we know already a lot about weak points of knowledge of elementary school and secondary school teachers, and we also know about conditions that help them to develop their knowledge. However, the very notion of knowledge is itself problematic. For example, when we speak of mathematics knowledge, to what do we pay most attention? To knowing facts, conventions, and representations? To knowing concepts, relationships, and procedures? To the ability of solving problems? To mathematical processes such as representing, modeling, reasoning, establishing connections, and communicating? To wider issues such as mathematical appreciation? Similar questions may be posed regarding the knowledge of mathematics pedagogy. We still have a long way to go until, as a research community, we reach some level of consensus about the relative role, importance, and mutual relationships among the different aspects of knowledge.

Many papers in JMTE-although in lesser number-address teachers' practice. The prevalent issue tends to be how professional practices are aligned with the curriculum and how they may be promoted by different teacher education settings. Some authors address practice in a very general way-either as traditional or as reformed oriented practiceswhereas others look at more specific aspects of practice, such as selecting and proposing tasks to the students and conducting students' activity on these tasks. The notion of practice is perhaps even more problematic than the notion of knowledge, requiring an epistemological discussion that is still under way. When we consider practice, do we place our attention on behaviors and actions of the participants or their intentions and meanings? How do we connect individual and social aspects of practices? For a given group of teachers, how is "good practice" established-under what criteria and what processes? How do professional practices develop?

Finally, a still lesser but growing number of papers deal with issues of identity. Whereas this notion is being addressed only quite recently in mathematics teacher education, it has a long tradition in other fields such as psychology (often regarded as "self"), sociology, and anthropology (with a focus on social and cultural identity). In some sense, we may regard the abundant research on teachers' beliefs of the 1980s and 1990s as addressing a vital aspect of teachers' identity-what they believe regarding issues that are central to their professional role, such as their view on the nature of mathematics, what is most important in the mathematics curriculum, how students' learn, and how to go about teaching them. As human beings, we hold multiple identities, as citizens of some country, and as members of some family, professional group, several informal networks, and so on, often with conflicting requirements. Of course, the notion of identity is also very problematic, concerning its individual and collective aspects, social and institutional constrains, agency possibilities, and processes of development.

This broad framework of knowledge, practice, and identity provides an entry point to look at the papers in this issue of JMTE. However, looking at teachers' learning on these different levels, we also need to pay attention to the settings, tools, and processes that support such learning. In addition, it is interesting to consider the analytical tools that researchers use to make sense of their data and to construct new knowledge.

Two of the papers in this issue have a focus on practice. Karin Brodie and Yael Shalem address the notions of teacher practice and teacher learning. The authors discuss in depth the notion of practice that they regard as involving particular forms of knowledge, skills, and technologies. They also consider learning central to practices since social goods and 
social goals evolve, entailing new means of achieving them. They suggest two key aspects in a practice, the criteria for deciding what counts as appropriate actions in that practice and how the community of practitioners holds the participants to account to such criteria, thus contributing to the wider discussion on these issues.

Charalambos Charalambous, Heather Hill, and Deborah Ball also address the notion of practice, in this case the very specific practice of providing instructional explanations. They are concerned not only with this practice but also with the ways prospective teachers may learn it. An underlying assumption of this paper is that teacher education curricula must be grounded in the "core practices of teaching" which requires the identification of such core practices and their "components."

On the other hand, Michal Tabach, Esther Levenson, Ruthi Barkai, Pessia Tsamir, Dina Tirosh, and Tommy Dreyfus address secondary school teacher knowledge, aiming to investigate critical elements of teachers' knowledge of proof, both regarding universal and existential statements. In this way, at the center of this paper is proof, a specific aspect of mathematics knowledge. Interestingly, the notion of practice is touched upon in the very last paragraph of the paper as the authors relate their findings to the teacher classroom activity.

And finally, AnnaMarie Conner, Kelly Edenfield, Brian Gleason, and Filyet Ersoz focus on beliefs about mathematics, teaching, and proof. In contrast with the previous paper, in which proof is always at the forefront, in this case, proof is just an aspect of mathematics teaching and learning. Belief, a notion strongly related to identity, is the important concept in this paper. The authors address issues related to knowledge when they discuss prospective teachers' views on the nature of mathematics as instrumentalist, Platonist, or problem solving. They still address issues of knowledge when they discuss prospective teachers' ability to identify correctly right and wrong proofs as well as their views on the role of informal proofs in secondary mathematics. They also come close to the notion of practice when they frame beliefs about mathematics teaching in two broad categories: (1) traditional or teacher centered and (2) reformed based or student centered.

Let us now turn to issues of professional development settings and tools to support teacher learning. In teacher education, an inescapable distinction concerns the participants. Working with prospective teachers, in many respects, raises different issues from working with practicing teachers. Whereas the primary responsibility of practicing teachers is to promote the mathematics learning of their students, in the frame of broader social and educational goals, the primary responsibility of prospective teachers is to develop themselves to become competent mathematics teachers. The primary practice of practicing teachers is professional practice, and the primary practice of prospective teachers is their learning practice.

Two of the papers deal with prospective teacher education settings. The participants in the Charalambous, Hill, and Ball paper are prospective elementary and middle school teachers. They take courses aiming to develop knowledge, skills, and ways of reasoning that support effective mathematics teaching. Besides learning mathematical ideas and processes, these courses seek to provide them opportunities to practice using representations, providing explanations, and analyzing the thinking of others. A key idea is "learning to unpack one's thinking through the use of representations as explanatory tools." Course activities usually follow the pattern of working individually and in small groups and ending with a whole-class discussion.

Conner et al. studied six secondary prospective mathematics teachers approaching the final stage of their academic preparation. The first course they attended had a focus on mathematics (connections) and was taught by involving participants in doing mathematical 
investigations in small groups followed by whole-class discussions. Great attention was given to the criteria on selection of tasks. The second course focused on pedagogy (methods) and focused on teaching practices including planning, task design, and questioning. In this paper, the most important learning tools seem to be the authentic character of the mathematical experiences (in the connections course) and the alignment with curriculum orientations (in the methods course). In both courses, the whole group discussions and the extended opportunities for reflection seem to be also important to promote changes in the participants.

In contrast, Brodie and Shalem worked with a large group of practicing teachers. They constructed a professional development program following features such as focus on learners' thinking (particularly learners' errors in specific concepts), design of and reflection on lessons, and tasks and activities, aiming to promote and sustain professional learning communities. A very important feature of this program was the reporting of activities from the small groups to the large group, leading to the development of accountability conversations, so that teachers were developing accountability to each other and to the profession. The 50 participants in the study by Tabach et al. were also practicing teachers. They were not object of a specific intervention regarding the aim of the study; however, it is interesting to note that $80 \%$ of them were studying for a Master's degree.

Finally, let us take a look at the analytical tools and major findings provided by the authors. Tabach et al. took into consideration if proofs concerned universal or existential statements (an epistemological aspect) and if they were verbal or symbolic (a kind of representation). They found that teachers pay strong attention to the structure of the proof or mode of argumentation as the first step in the analysis of the validity of a proof. They also suggest that teachers tend to overlook the strengths of verbal proofs, regarding them as deficient, and overstate the value of symbolic justifications, without noticing their possible pitfalls. In this way, they provide important elements for those involved in teacher education (prospective and practicing) regarding teachers' knowledge and instructional practice on proof.

In their work, Conner, Edenfield, and Ersoz give prominence to the construct of "belief structure." They report relatively stable beliefs regarding mathematics and proof and changing beliefs regarding mathematics teaching, from a teacher-centered view to a view that put emphasis on students' activities and understandings. In their perspective, by classifying the participants' belief structures as naïve idealist, isolationist, naïve, and reflective connectionist, they explain changes that they observed in the participants' beliefs about teaching as they had rich mathematical experiences, involving investigations and discussions, and they pay attention to specific aspects of task design and classroom work.

Charalambous, Hill, and Ball relate their findings to substantive and syntactic knowledge of content, suggesting that stronger knowledge means more ability in providing explanations, and underline the value of using representations as explanatory tools. In their view, active and deliberate reflection on practice contributes to prospective teachers' growth in providing explanations. Another factor that they indicate may contribute to this learning is developing alternative images of teaching, and, in particular, of providing explanations. This attention to core practices of mathematics teaching in the frame of current curriculum orientations is definitively an important priority for researchers in our field.

Finally, Brodie, and Shalem propose the notions of "challenge" and "solidarity" as key constructs to support developing accountability conversations among teachers. They strive to show that their professional development program supported teachers to challenge each other and to build solidarity with each other. Through this process, they claim that teachers 
developed accountability to each other and to the profession, regarding their practices and their learning. With this work, the authors provide very interesting notions concerning teachers' practices and teachers' learning that may challenge and stimulate other researchers and teacher educators in framing their own studies and professional development programs.

Acknowledgments The writing of this Editorial was supported by national funds through FCT—Fundação para a Ciência e Tecnologia in the frame of the Project Professional Practices of Mathematics Teachers (contract PTDC/CPE-CED/098931/2008). 